Article

\title{
Modeling the Potential Global Distribution of Phenacoccus madeirensis Green under Various Climate Change Scenarios
}

\author{
Jiufeng Wei ${ }^{1, \dagger}{ }^{,}$Xiaozhou Li ${ }^{2,+}$, Yunyun Lu ${ }^{1}$, Ling Zhao ${ }^{1}$, Hufang Zhang ${ }^{3}$ and Qing Zhao ${ }^{1, *}$ \\ 1 Department of Entomology, Shanxi Agricultural University, Taigu 030801, China \\ 2 School of Light Industry Science and Engineering, Qilu University of Technology (Shandong Academy of \\ Sciences), Jinan 250300, China \\ 3 Department of Biology, Xinzhou Teachers University, Xinzhou 034000, China \\ * Correspondence: Zhaoqing86623@163.com; Tel.: +86-136-5354-9074 \\ + These authors contributed equally to this work.
}

Received: 1 August 2019; Accepted: 4 September 2019; Published: 6 September 2019

\begin{abstract}
The Madeira mealybug, Phenacoccus madeirensis Green, is a serious invasive pest that does significant damage to more than 120 genera of host plants from 51 families in more than 81 countries. However, the potential distribution range of this pest is unclear, which could hamper control and eradication efforts. In the current study, MaxEnt models were developed to forecast the current and future distribution of the Madeira mealybug around the world. Moreover, the future potential distribution of this invasive species was projected for the 2050s and 2070s under three different climate change scenarios (HADGEM2-AO, GFDL-CM3, and MIROC5) and two representative concentration pathways (RCP-2.6 and RCP-8.5). The final model indicates that the Madeira mealybug has a highly suitable range for the continents of Asia, Europe, and Africa, as well as South America and North America, where this species has already been recorded. Potential expansions or reductions in distribution were also simulated under different future climatic conditions. Our study also suggested that the mean temperature of the driest quarter (Bio9) was the most important factor and explained $46.9 \%$ of the distribution model. The distribution model from the current and future predictions can enhance the strategic planning of agricultural and forestry organization by identifying regions that will need to develop integrated pest management programs to manage Madeira mealybug, especially for some highly suitable areas, such as South Asia and Europe. Moreover, the results of this research will help governments to optimize investment in the control and management of the Madeira mealybug by identifying regions that are or will become suitable for infestations.
\end{abstract}

Keywords: Madeira mealybug; MaxEnt; worldwide species distribution modeling; RCP scenarios

\section{Introduction}

Insects are the most diverse and pervasive set of species on earth [1]. Invasive insect pests can significantly affect agricultural productivity, forest resources, and human health [2]. The largest food-producing countries, such as China and the United States, face the highest potential losses from invasive insects [3]. The cost of controlling and managing invasive insects is estimated to be a minimum of US $\$ 70$ billion - far greater than the cost of healthcare, which is $\$ 6.9$ billion per year globally [3]. More than 450 species of alien insects, most of which are herbivores, have fed on various plants since European settlement in the United States, and $14 \%$ of these insects have caused large monetary losses [4].

Scale insects are major agricultural and forestry pests that are extremely invasive, and damage plants through sap loss [5]. For example, scale insects account for only $1 \%$ of the total insect fauna of 
the United States, but 13\% of the introduced insect fauna, and on average one new invasive insect is introduced to the United States per year [6]. The Madeira mealybug, Phenacoccus madeirensis Green (Hemiptera: Pseudococcidae), is a notorious, global invasive pest that feeds on all parts of the host plant, causing damage to more than 130 genera of host plants from 51 families [5]. Controlling the Madeira mealybug is of particular interest to agriculture and forestry, as this species can harm a variety of crops, such as pineapple [7], cotton [8], cassava [9], potatoes [10], eggplant [10], citrus fruit [11], and passion fruit [12]. Also, P. madeirensis causes the most significant damage to greenhouse ornamental plants that are grown in the Southeastern Unites States [13]. In Georgia, an estimated \$71 million of damage was caused to ornamental plants in 2001 by the Madeira mealybug and other scale insects [14]. In Asia, especially in India, the Madeira mealybug occurs in more than $90 \%$ of cotton-producing areas and has caused economic losses [8]. Manihot esculenta is a major food crop in many regions of Africa [15], the Americas [16], and Asia, and it is also affected by the Madeira mealybug. These data suggest that P. madeirensis is a serious threat to the production of food crops, fruits, vegetables, and ornamental plants (e.g., Pelargonium (L.), Kalanchoe blossfeldiana Poelin, Ocimum basilicum L.) worldwide [11].

$P$. madeirensis is endemic to neotropical regions, although it was first described from specimens collected on Madeira Island, Portugal in 1923 [17,18]. It is now widely distributed in more than 81 countries [5]. So far, this invasive species has expanded its native range to North America, Africa, Asia, and Europe [5,11]. In Europe, it was first recorded in Italy in 1981, and then rapidly spread across the Mediterranean [11,19-25]. The Madeira mealybug was first reported in Japan, and then continued to invade other Asian countries [26], causing serious damage in Asia, particularly in China [27,28], the Philippines [8], Thailand [29], Vietnam [30], and Pakistan [31]. Given the increasingly global nature of transport and trade, there is an urgent need to control and manage this pest because of its rapid spread and wide host range. If this pest is not controlled, it may spread further to other regions and threaten agriculture and forestry, especially cassava, cotton, and ornamental plants.

Identifying potential habitat extents under various climate change scenarios is necessary to develop strategies to limit the introduction and expansion of invasive species [32]. However, incomplete distribution data and the range of invasive species often make control and eradication efforts less effective [33]. Species distribution models provide a powerful tool to help with pest management. Many studies have investigated the physiology and negative effects of the Madeira mealybug [27,34], but its distribution pattern is relatively unknown. In addition, the future distribution of the Madeira mealybug will likely expand or contract due to the continued effects of global warming. However, to date, there have been no studies that forecast the Madeira mealybug's potential distribution under climate change scenarios based on its current distribution sites. Thus, the potential distribution extents under climate change scenarios are evaluated in the current study. Moreover, two goals were also approached in the current study: (1) identifying the trends of suitable habitat range for the Madeira mealybug under different climate change scenarios around the world, and (2) identifying the key environmental variables that constrain the potential distribution of this pest.

\section{Materials and Methods}

\subsection{Species Data}

Georeferenced occurrence data of P. madeirensis Green were compiled from the following sources: the Global Biodiversity Information Facility (GBIF, https://www.gbif.org/), the Center of Agriculture and Bioscience International (CABI, https://www.cabi.org), the European and Mediterranean Plant Protection Organization (EPPO, https://www.eppo.int), Scalenet (http://scalenet.info), and other existing literature, as listed in Table S1. Geocoordinates for each distribution site were referenced from the data in the literature or by using Google Maps. Potential errors in the distribution information and duplicate occurrences were excluded. For example, data indicating the locations of province or state were removed, but data referring to the county, city, and town were retained. An initial dataset 
containing 124 georeferenced occurrences was compiled, of which 15 were in the Madeira mealybug's native range and 109 records were from its invasive range.

Geographical biases in the distribution records were associated with sampling near cities or other areas that are easily accessible to collectors $[35,36]$. This collection bias often leads to environmental bias and can adversely affect model calibration by causing the overrepresentation of certain environmental features that are characteristic of more accessible and extensively surveyed areas [37]. Sampling bias can be addressed by reducing the number of distribution sites in oversampled regions using spatial filtering [38]. To reduce the sample bias of the occurrence points, a coarse resolution (grid cell of $5 \mathrm{~km} \times 5 \mathrm{~km}$; consistent with the resolution of the environment variable) was created and a single point was randomly extracted from each grid cell, which included two or more sampling points $[39,40]$. After filtering, 117 distribution records remained, including the native range ( 15 points) and the invaded regions (102 points). The list of distribution sites and the map are shown in Figure 1 and Table S2. The workflow was conducted in ArcGIS 10.1 (ESRI, Redlands, CA, USA) (http://www.esri.com/).

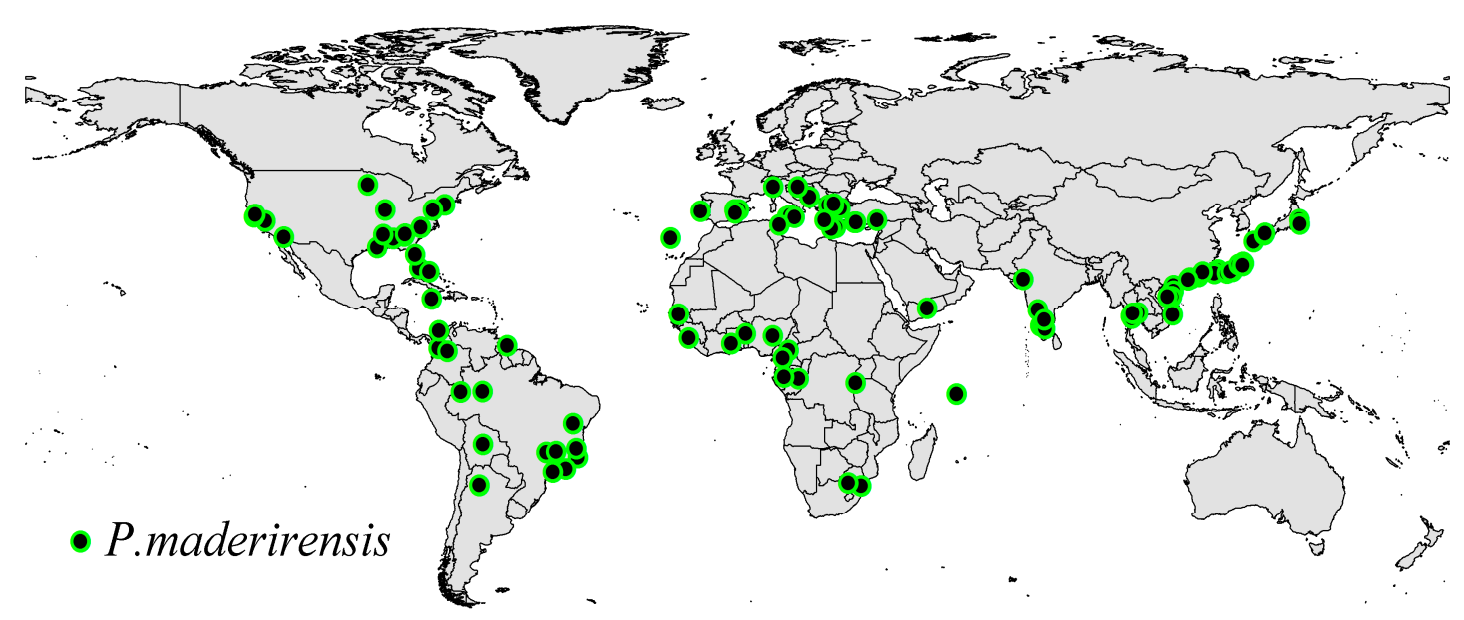

Figure 1. The occurrence sites used for the forecast of the potential distribution of P. madeirensis.

\subsection{Environmental Variables}

Climatic variables are the main factors that determine species niches and have been used frequently for large-scale insect niche modeling [41,42]. At a broad scale, precipitation and temperature are two principal climate factors that constrain the species distribution range [43]. Thus, a set of 19 current global climate data points with an interpolated spatial resolution of $2.5 \mathrm{arc} \min (\sim 5 \mathrm{~km}$ resolution at the equator) were used in this study, as obtained from the WorldClim Global Climate Database, version 1.4 (https://www.worldclim.org/) [44]. Minima, maxima, and average values of monthly, quarterly, and annual ambient temperature and precipitation values, recorded from 1950 to 2000, were included to represent the current climate conditions.

Multicollinearity among climate variables may affect the analysis of species-environment relationships [45]. Hence, to minimize multicollinearity, a Pearson's correlation coefficient for each pairwise comparison of all 19 climatic variables was used to identify and remove highly correlated variables $\left(R^{2} \geq|0.8|\right)$ (Table S3). Multicollinearity was assessed using ENMTools version 1.0 [46]. Five bioclimate environmental variables were retained in the final analysis: mean diurnal range (mean of monthly (max temp - min temp)) (Bio2), isothermality (Bio2/Bio7) $(\times 100)($ Bio3), mean temperature of driest quarter (Bio9), precipitation seasonality (coefficient of variation) (Bio15) and precipitation of coldest quarter (Bio19).

Given the uncertainty of future climate scenarios, impact assessments need to incorporate data from a range of climate models that are effective at simulating historical climate changes over the area of interest [47]. To account for uncertainty in future scenarios, three random global circulation models (GCMs) were downloaded from the Worldclim database with a spatial resolution of $2.5 \mathrm{arc}$ 
min to estimate future distribution ranges in the current research: the Hadley Global Environment Model 2-Atmosphere Ocean (HADGEM2-AO), the Geophysical Fluid Dynamics Laboratory Coupled Model V3 (GFDL-CM3) and the Model for Interdisciplinary Research on Climate (MIROC5) for 2050 (the average for 2041-2060) and 2070 (the average for 2061-2080) were obtained from the Coupled Model Inter-comparison Project Phase 5 (CMIP5) of the fifth assessment of the International Panel on Climate Change (IPCC) [48].

The representative concentration pathways (RCPs) represent the full bandwidth of possible future emission trajectories. Four RCPs, ranging from the lowest (RCP 2.6) to highest (RCP 8.5), were coded according to a possible range of radiative forcing values in the year 2100 relative to preindustrial values $\left(+2.6,+4.5,+6.0\right.$, and $+8.5 \mathrm{w} / \mathrm{m}^{2}$, respectively). RCP 2.6-2050 (the average for the years 2041-2060 under scenario RCP 2.6), RCP 8.5-2050 (the average for the years 2041-2080 under the scenario RCP 8.5), RCP 2.6-2070 (the average for the years 2041-2080 under the scenario RCP 8.5), and RCP 8.5-2070 (the average for the years 2061-2080 under the scenario RCP 8.5) were selected as models of the future influence of the potential distribution of the Madeira mealybug to analyze scenarios under extreme climatic variations, and highlight the different scenarios that may significantly affect the geographical distribution patterns of the Madeira mealybug.

\subsection{Modeling Approach}

Numerous programs are used to assess the potential distribution of invasive insect species, such as CLIMEX [49], BIOCLIM [50], and GARP [51]. However, MaxEnt performs particularly well for modeling small and presence-only data on the current and future distribution of invasive species [52]. MaxEnt is a general-purpose machine learning method with a precise mathematical formulation; it has a number of aspects that make it well suited for species distribution modeling, such as using a regularization multiplier to control model complexity, and thus avoids overfitting [53]. Thus, numerous studies have used MaxEnt to predict the potential distribution of invasive pests under climate change, such as the common ambrosia beetle [54] and large pine weevil [55]. In addition, MaxEnt generates a response curve for each environmental predictor, which is essential for interpreting and comparing the performances of models [56]. Therefore, the potential distribution of the Madeira mealybug under current and projected climate scenarios was investigated using MaxEnt version 3.4.1 [57]. The MaxEnt model applied a machine learning method called maximum entropy modeling, which follows the principle of maximum entropy. The entropy formula is defined as below:

$$
H(\hat{\pi})=-\sum_{x \in X} \hat{\pi}(x) \ln \hat{\pi}(x),
$$

where $\pi$ is the unknown probability distribution; $\hat{\pi}$ is the approximation of $\pi ; X$ is a finite set; $x$ is an individual element in set $X$; and $\ln$ is the natural logarithm. The entropy is nonnegative and is at most the natural log of the number of elements in $X$.

Usually, feature types and a regularization multiplier are employed to optimize models and control for overparameterization in MaxEnt. These feature types represent different transformations of the covariates, including linear, product, hinge, threshold, and quadratic features, which allow the software to be optimized for the species of interest and prevent oversimplified or overcomplicated models. Hence, in order to produce the best possible model for pests, the R package "ENMeval" was used to avoid overfitting and optimize model parameters, including regularization multipliers and the combination of feature classes in the current study. "ENMeval" executes a set of automated models to compute several estimators, yielding a comparable evaluation of all possible models [58]. The regularization multipliers ranged from 0.5 to 4 in increments of 0.5 , and 8 FCs were tested for the Madeira mealybug: (1) Linear (L); (2) Linear (L) and Quadratic (Q); (3) Linear (L), Quadratic (Q) and Hinge (H); (4) Linear (L), Quadratic (Q), Hinge (H), and Product (P); (5) Linear (L), Quadratic (Q), Hinge $(\mathrm{H})$, Product $(\mathrm{P})$, and Threshold $(\mathrm{T}) ;(6)$ Quadratic $(\mathrm{Q})$, Hinge $(\mathrm{H})$ and Product $(\mathrm{P})$; (7) Quadratic $(\mathrm{Q})$, Hinge $(\mathrm{H})$, Product $(\mathrm{P})$, and Threshold $(\mathrm{T})$; and $(8)$ Hinge $(\mathrm{H})$, Product $(\mathrm{P})$ and Threshold $(\mathrm{T})$. In this 
study, the "checkerboard2" approach was used to calculate the Akaike information criterion coefficient (AICc), and the lowest delta AICc scores were selected to run the final MaxEnt models. The ENMeval package was implemented in R 3.1.3. The result are shown in Figure S1 and Table S4. The regularization multiplier is 1.5 and feature combinations of LQHPT were selected for our analysis. The logistic output of MaxEnt was used to run the model. The 10th percentile training presence logistic threshold was used to define the suitable and unsuitable habitats for the Madeira mealybug. This threshold is widely used in species distribution modeling, especially when data are collected by different observers and methods over a long period of time [59]. The potential distribution map was reclassified into four levels based on the following thresholds: <threshold indicates an unsuitable habitat; threshold-0.4 indicates low habitat suitability; $0.4-0.6$ indicates moderate habitat suitability and $0.6-1$ indicates high habitat suitability. Finally, 10-fold cross-validation was executed to run MaxEnt to prevent random errors from the predicted samples. In addition, a final suitability map was created by averaging the maps from the three future climate scenarios to reduce the uncertainty among GCMs.

\subsection{Model Evaluation}

The receiver operating characteristic (ROC) area under the curve (AUC) is often used to assess the performance of MaxEnt; however, there are some disadvantages to this approach for our study. This approach weighs the omission and commission errors equally, and AUC also does not provide information on the spatial distribution of model errors [60]. Thus, a partial receiver operating characteristic (pROC) metric approach was employed to assess the robustness of the model by Niche Toolbox (http://shiny.conabio.gob.mx:3838/nichetoolb2/) with 1000 replicates and E $=0.05$ [61].

\section{Results}

\subsection{Model Performance}

The test of the model performance yielded optimal results for partial ROC (mean AUC: 0.9177406) and the distribution of AUC ratios calculated as AUCpartial/AUCrandom was significantly greater than random expectations showing high performance $(p<0.0001)$ (Figure S2). A "10th percentile training presence logistic threshold" value of 0.2126 was obtained for $P$. madeirensis. Therefore, the threshold at below 0.2126 indicates an unsuitable habitat for this species.

\subsection{Importance of Environmental Variables}

Of the five climatic variables that were tested, the relative contributions of each environmental variable to the final model showed that the mean temperature of the driest quarter (Bio9) was the largest contributor $(46.9 \%)$ that constrained the potential distribution map of P. madeirensis. Mean diurnal range (Bio2) had the second largest contribution and accounted for $21.6 \%$ of the model (Table 1). These two factors explained $68.5 \%$ of the potential distribution range. Other factors, such as isothermality (Bio2/Bio7) (Bio3), precipitation of coldest quarter (Bio19) and precipitation seasonality (coefficient of variation) (Bio15) contributed to the potential distribution map by $13.1 \%, 10.8 \%$, and $7.5 \%$, respectively. The result of the model implies that the thermal condition was more important than other environmental variables in the potential distribution model of $P$. madeirensis.

Table 1. Relative contribution of each environmental variables to the MaxEnt model.

\begin{tabular}{cc}
\hline Environmental Variables & Relative Contribution \\
\hline Mean Diurnal Range (Bio2) & $21.6 \%$ \\
Isothermality (Bio2/Bio7) (×100) (Bio3) & $13.1 \%$ \\
Mean Temperature of Driest Quarter (Bio9) & $46.9 \%$ \\
Precipitation Seasonality (Coefficient of Variation) (Bio15) & $7.5 \%$ \\
Precipitation of Coldest Quarter (Bio19) & $10.8 \%$ \\
\hline
\end{tabular}




\subsection{Current Potential Distribution Range}

The current distribution pattern of P. madeirensis was created based on the current climate and occurrence records (Figure 2). The current distribution map suggested that Southern Asia, Europe, Central Africa, most parts of South America, and Central America have suitable environmental conditions for P. madeirensis. North America and Australia showed scattered distributions of P. madeirensis. In Asia, Southern China, most parts of Vietnam, Cambodia, Laos, Southern Thailand, Sri Lanka, South and East India, northern Philippines, and some islands of Indonesia have environments with high suitability for P. madeirensis. Iceland, countries bordering the Mediterranean Sea, the United Kingdom, and Ireland also have suitable environments with high risk for P. madeirensis in Europe. Northern Egypt, Libya, Tunisia, Algeria, Northeastern Morocco and the Western Sahara, Central Africa, and Madagascar likely have highly suitable environments as well. Australia, New Zealand, and Papua New Guinea also showed high suitability for P. madeirensis. In addition, Southeastern America, Central America, and South America had high invasion risks under the current climate scenario. In its native range, most of Brazil, Guyana, Ecuador, and Bolivia were highly suitable for P. madeirensis. Based on the current climate variables, the total range or area of potential suitable habitat for $P$. madeirensis was predicted to be approximately $12.95 \times 106 \mathrm{~km}^{2}$, of which about $1.71 \times 106 \mathrm{~km}^{2}$ (nearly $13.20 \%$ of the total suitable range) showed high habitat suitability, and about $4.11 \times 106 \mathrm{~km}^{2}$ (approximately $31.73 \%$ of the total potentially suitable area) showed moderate habitat suitability (Table 2).

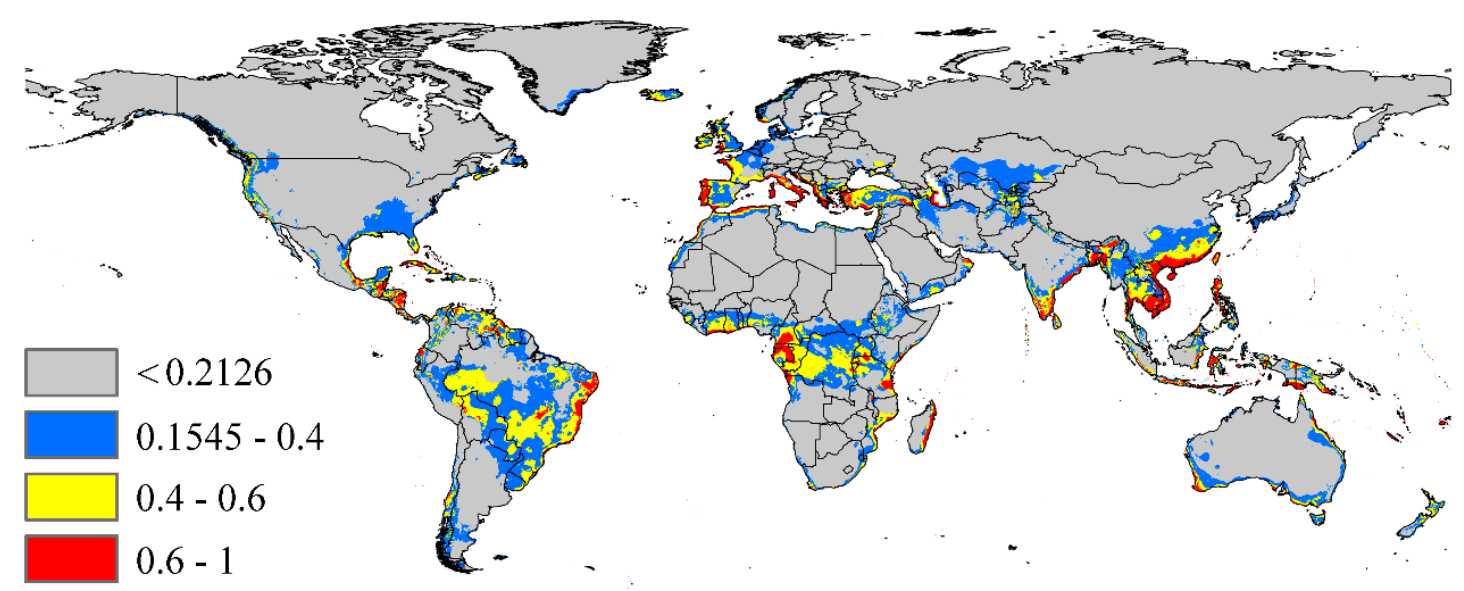

Figure 2. The potential distribution of Phenacoccus madeirensis Green used in the current modeling. Gray, unsuitable habitat area; blue, low habitat suitability area; yellow, moderate habitat suitability area; red, highly habitat suitability area.

Table 2. Predicted suitable areas for two invasive species under current and future climatic conditions $\left(\mathrm{km}^{2}\right)$.

\begin{tabular}{ccccccc}
\hline \multicolumn{2}{c}{ Level } & Current & RCP 2.6-2050 & RCP 8.5-2050 & RCP 2.6-2070 & RCP 8.5-2070 \\
\hline \multirow{2}{*}{ LHS } & \multirow{2}{*}{$0.2126-0.4$} & $\sim 7.13 \times 10^{6}$ & $\sim 7.24 \times 10^{6}$ & $\sim 6.84 \times 10^{6}$ & $\sim 11.50 \times 10^{6}$ & $\sim 6.61 \times 10^{6}$ \\
& & & $(1.5 \%)$ & $(-4.06 \%)$ & $(61.2 \%)$ & $(-7.29 \%)$ \\
MHS & $0.4-0.6$ & $\sim 4.11 \times 10^{6}$ & $\sim 3.41 \times 10^{6}$ & $\sim 3.34 \times 10^{6}$ & $\sim 6.77 \times 10^{6}$ & $\sim 3.42 \times 10^{6}$ \\
& & $(-17.03 \%)$ & $(-18.73 \%)$ & $(64.72 \%)$ & $(-16.79 \%)$ \\
\multirow{2}{*}{ HHS } & $0.6-1$ & $\sim 1.71 \times 10^{6}$ & $\sim 1.21 \times 10^{6}$ & $\sim 1.20 \times 10^{6}$ & $\sim 2.97 \times 10^{6}$ & $\sim 1.19 \times 10^{6}$ \\
& & $(-29.23 \%)$ & $(-29.82 \%)$ & $(73.68 \%)$ & $(-30.40 \%)$ \\
\multirow{2}{*}{ THS } & $0.2126-1$ & $\sim 12.95 \times 10^{6}$ & $\sim 11.86 \times 10^{6}$ & $\sim 11.39 \times 10^{6}$ & $\sim 21.26 \times 10^{6}$ & $\sim 11.21 \times 10^{6}$ \\
& & & $(-8.41 \%)$ & $(-12.04 \%)$ & $(64.16 \%)$ & $(-13.43 \%)$ \\
\hline
\end{tabular}

LHS: Low habitat suitability; MHS: Moderate habitat suitability; HHS: high habitat suitability; THS: total habitat suitability.

Response curves show the quantitative relationship between environmental variables and the logistic probability of presence (known as habitat suitability) and can deepen our understanding of the ecological niche of the species. The responses of five environment variables to $P$. madeirensis are 
illustrated in Figure 3. Based on response curves, two main climatic factors that were associated with high suitability were temperatures of $2-10^{\circ} \mathrm{C}$ for Bio2 and $15-27^{\circ} \mathrm{C}$ for Bio9. Other climate conditions also showed a relationship to high habitat suitability, such as $2.5-6^{\circ} \mathrm{C}$ for Bio3, 80-100 mm for Bio15, and 40-500 $\mathrm{mm}$ for Bio 19.
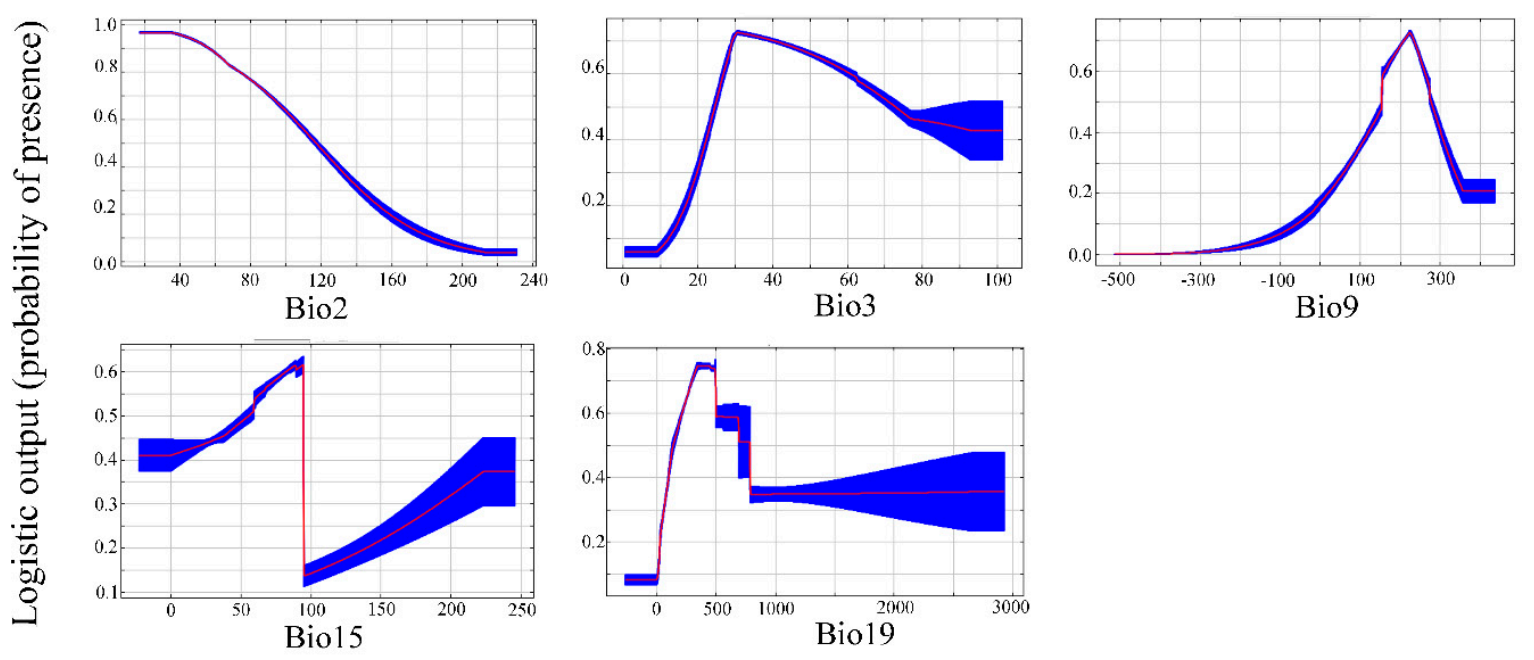

Figure 3. Response cures showing the relationships between the probability of presence of pest and five bioclimatic variables. Values shown are the average over 10 replicate runs; blue margins show \pm SD calculated over 10 replicates.

\subsection{Future Invasion Range}

Model transfers to future conditions of $P$. madeirensis found a similar pattern to the present day (Figure 4). The potential distribution range of $P$. madeirensis was larger than the current environmental variables under climate change (Table 2 ).

The predicted area gains in the area of suitable habitat were predicted to be about $11.86 \times 106 \mathrm{~km}^{2}$, which was $8.41 \%$ lower than the current conditions when compared to condition RCP 2.6-2050 (Figure 4A and Table 2). The highly suitable area was reduced to $1.21 \times 106 \mathrm{~km}^{2}$ under these climate scenarios, of which there was a $29.23 \%$ decrease over the current highly suitable areas. The highly suitable areas were markedly reduced in Southern China, Central Africa and northeastern India. Under RCP 8.5-2050, both the suitable habit and highly suitable habit decreased relative to present-day conditions. The areas were reduced by $12.04 \%$ and $29.82 \%$ for suitable habitats and highly suitable habitats, respectively (Figure 4B and Table 2).

Under the future climate scenario of RCP 2.6-2070, the areal extent of gains amounted to $21.26 \times 106 \mathrm{~km}^{2}(64.16 \%$ of the currently suitable habitat area) (Figure 4C and Table 2). Expansions in the area signification increased with the warming of the climate, especially in Southern China and Europe. The area of highly suitable habitat expanded to $2.97 \times 106 \mathrm{~km}^{2}$ (a $73.68 \%$ increase of the currently highly suitable habitat area), and this pattern is accentuated in Southern China and Eastern Europe.

The MaxEnt predictions of gains in suitable habitat areas under the future climate scenario/year combination RCP 8.5-2070 also showed a decrease near $11.21 \times 106 \mathrm{~km}^{2}$ (a $13.43 \%$ reduction in the currently suitable habitat areas) (Figure 4D and Table 2). The highly suitable area might reduce by $30.40 \%$ under this scenario, constricting the area to $1.19 \times 106 \mathrm{~km}^{2}$. The restricted range was predicted to increase the highly suitable areas in Southern China and Eastern Europe, but the model predicted a constriction of suitable habit areas in some regions, such as countries around the Mediterranean Sea, South America, Africa.

In summary, the potential distribution of P. madeirensis will shrink with climate change, reducing both the total suitable habit and the highly suitable habitat in the three future climate scenarios that 
were tested. The area of high habitat would reach a peak under RCP 2.6-2070 and a significant decline under the other three climate conditions.

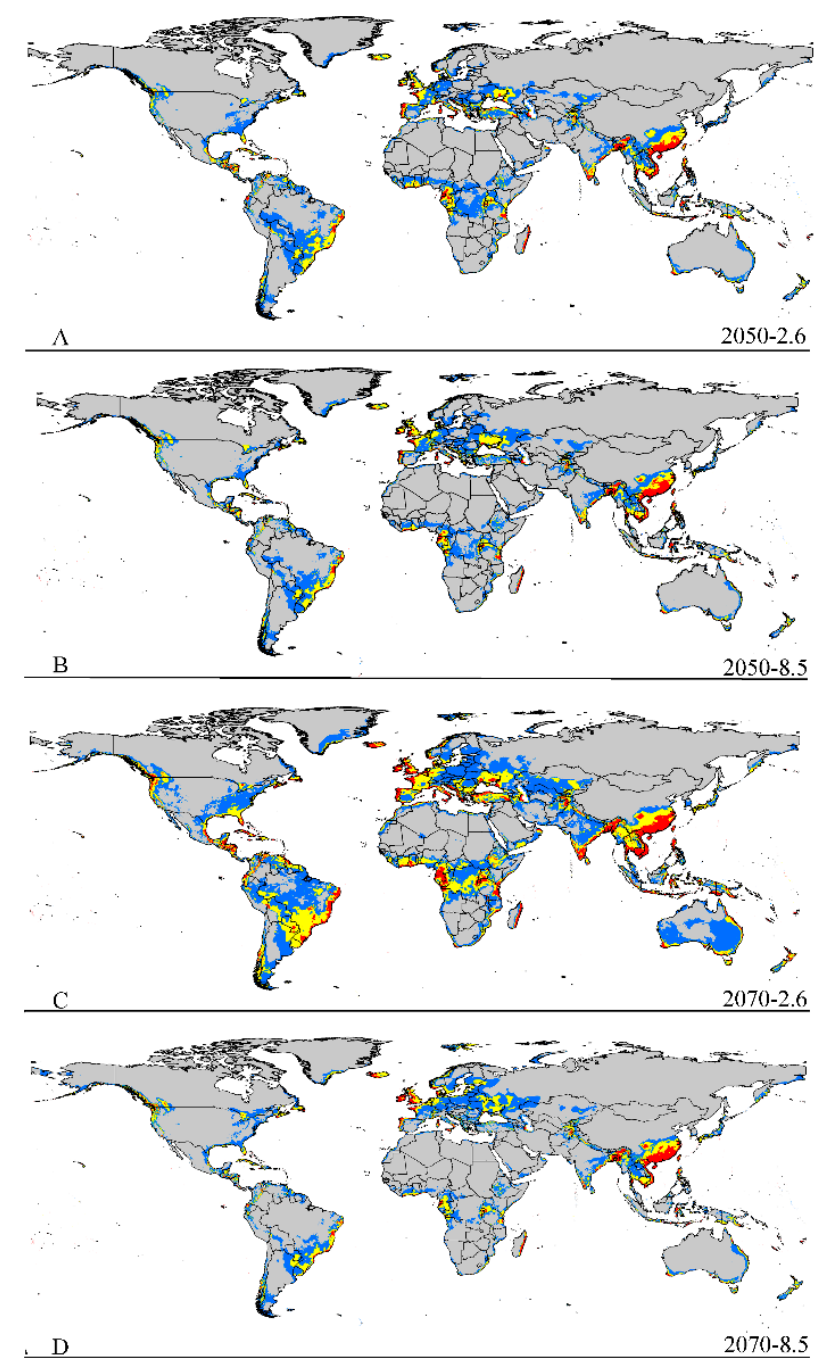

Figure 4. Future species distribution models of Phenacoccus madeirensis on a global scale under different climate scenarios predicated by MaxEnt. Gray, unsuitable habitat area; blue, low habitat suitability area; yellow, moderate habitat suitability area; red, highly habitat suitability area. RCP: Representative Concentration Pathway. (A) RCP 2050-2.6; (B) RCP 2070-2.6; (C) RCP 2050-8.5; (D) RCP 2070-8.5.

\section{Discussion}

A global dataset of occurrences of the Madeira mealybug and MaxEnt were employed to forecast the potential distribution of this species under current and future climate conditions. The models performed very well for predicting the suitable habitat range of $P$. madeirensis when evaluated using partial ROC. The model indicates several climatic variables that constrain the current distribution of $P$. madeirensis. Most of the regions invaded by $P$. madeirensis have a warm climate. Regions with extreme cold and heat are unsuitable for $P$. madeirensis under climate change. In spite of this, the most important factor that explained the current distribution was temperature. Mean temperature of the driest quarter (Bio9) and mean diurnal range (Bio3) explained 78.5\% of the current model. P. madeirensis can produce more than 250 eggs in a week at a constant temperature of $25^{\circ} \mathrm{C}$, and female mealybugs can complete development at $15-25^{\circ} \mathrm{C}$ under laboratory conditions [34]. Based on response curves, our model indicated that there would be an increase in the population of $P$. madeirensis when exposed to a mean temperature of $15-27^{\circ} \mathrm{C}$ in the driest quarter, predicting this as its most suitable temperature range. Thus, these temperature values could represent the most appropriate climatic conditions for the 
population growth of $P$. madeirensis. However, several highly suitable habitats in the current model would become unsuitable or shrink under climate change, such as its native range (South America) and its range in Europe. A possible reason for this decline in native habitat is global warming. In addition, the highly suitable range would shift to higher latitudes, such as in Europe, most likely because of rising temperatures making these areas more suitable for $P$. madeirensis.

The Madeira mealybug is native to South America but has already invaded other continents, such as Asia, North America, Europe, and Africa. The model predicted that climate change will significantly influence the worldwide distribution of $P$. madeirensis, but its effects will vary among different regions. Our model shows that $P$. madeirensis can invade most parts of the global landmass, such as Southern China, southern and eastern India, countries around the Mediterranean Sea, and Central Africa. The model also predicted that there would be a reduction of highly suitable and total habitat in the global range under climate versions RCP 2.6-2050, RCP 8.5-2050, and RCP 8.5-2070 relative to the present-day conditions. This result is not surprising. Many studies have shown similar results for various invasive species, such as the Giant African Snail [62], Schinus mole [63], Hyptis suaveolens [64], and Nitellopsis obtuse [65]. The range contraction that was predicted for P. madeirensis provides important information for its management and eradication. The shrinking climatic suitability of the current invaded range may make invasive species less competitive, potentially leading to their retreat [66]. Retreat by invasive pests could provide opportunities for the restoration of currently invaded landscapes, but further research is urgently needed to identify these opportunities and offer guidance for the management of pest species.

In addition, the model predicted a dramatic expansion in the future climatic model RCP 2.6-2070, which showed increased areas of suitability with plausible range shifts. These four prediction models suggest considerable uncertainty based on the current results. The uncertainty results from diverse sources, including distribution data quality, environmental datasets, modeling algorithms, model type, and model calibration parameters [67]. To minimize the uncertainty in the current study, resampling occurrences were limited to one per pixel, multicollinearity for climatic variables was minimized, and overparameterization was controlled for in MaxEnt. These methods were employed to minimize the uncertainty of the model [68].

In response to climatic change, most favorable habitat ranges shift based on the current climate model, including in its native and invasive ranges. The change of suitable habitat offers information for scientists or farmers looking to implement effective management strategies to control P. madeirensis. Many previous studies have focused on molecular identification [11,69], physiological characteristics $[13,34]$, and the chemical and biological control of P. madeirensis $[13,70]$. However, very few management strategies incorporate the spread of pests and the shift of distribution range due to climate change. Our model provides preliminary evidence for developing monitoring strategies to detect future infestations in currently uninfected regions by government agencies. Early warning monitoring is a critical step to develop management strategies for pests [71,72]. Species distribution models provide a cost-effective tool that can identify the most suitable areas for potential invasions. For example, our analysis suggests that $P$. madeirensis would find a highly suitable environment in Madagascar, Malaysia, Australia, and Iceland. In addition, some areas also show moderate suitable environments, into which P. madeirensis can expand under climatic change, such as Kazakhstan, Kyrgyzstan, and Azerbaijan. Highly and moderately suitable habitat areas predicted from our model can be used to formulate strict quarantine measures to prevent invasion. The results of the current research can help policy makers, extension organizations, and farmers to make adapted agricultural management decisions today when choosing planting areas that are less susceptible to the pest. In addition, prediction maps can give farmers information that can be used to help secure food production in the future when the Madeira mealybug is likely to expand its distribution range under climate change.

In summary, the results of the current study provide important information for identifying infected areas and making management decisions to control P. madeirensis globally. 


\section{Conclusions}

The current study projected the potential distributions of the Madeira mealybug under current and future climate change scenarios. First potential distribution maps for this pest were created based on current and future climate scenarios, and the results suggested that the future potentially suitable habitat area is far greater than the current distribution range. The current research provides a reference frame for quarantine departments and policymakers to manage and develop policies to control this pest. In addition, strict quarantine measures should be employed in areas where the Madeira mealybug has not yet been reported based on the results of current research. Other variables, such as the species' dispersal capacity, should be determined in future studies.

Supplementary Materials: The following are available online at http://www.mdpi.com/1999-4907/10/9/773/s1, Figure S1: Performances of niche model of pest. $\mathrm{L}=$ Linear; $\mathrm{Q}=$ Quadratic; $\mathrm{H}=$ Hinge; $\mathrm{P}=$ Product; $\mathrm{T}=$ Threshold, Figure S2: Partial AUC Values and Graphics, null model (red distribution), distribution of expectations created via bootstrapping replacement of $50 \%$ of the total available points and 1000 resampling replicates (blue distritbuion), Table S1: References used to compile the dataset, Table S2: Distribution sites for P. madeirensis, Table S3: Correlation analysis of environmental variables for P. madeirensis, Table S4: ENMeval results for P. madeirensis from SDMs.

Author Contributions: Conceptualization, J.W. and X.L.; methodology, J.W.; software, J.W. and X.L.; investigation, J.W. and X.L.; resources, J.W.; data curation, Y.L. and L.Z.; writing-original draft preparation, J.W. and Q.Z.; writing-review and editing, J.W. and L.Z.; project administration, H.Z.; funding acquisition, J.W., Q.Z. and H.Z.

Funding: This project was supported by the National Natural Science Foundation of China (NSFC) grant (nos. 31301899, 31501876, and 31872272) and Shanxi Agricultural University of Science and Technology Innovation fund projects (2015YJ03).

Acknowledgments: We thank the local plant protection stations of the agricultural department for their valuable fieldwork and collection of monitoring data. We thank the anonymous reviewers for their valuable comments.

Conflicts of Interest: The authors declare no conflict of interest. The funders had no role in the design of the study; in the collection, analyses, or interpretation of data; in the writing of the manuscript, or in the decision to publish the results.

\section{References}

1. Liebhold, A.M.; Berec, L.; Brockerhoff, E.G.; Epanchin-Niell, R.S.; Hastings, A.; Herms, D.A.; Kean, J.M.; McCullough, D.G.; Suckling, D.M.; Tobin, P.C.; et al. Eradication of invading insect populations: From concepts to applications. Annu. Rev. Entomol. 2016, 61, 335-352. [CrossRef] [PubMed]

2. Boyd, I.L.; Freer-Smith, P.H.; Gilligan, C.A.; Godfray, H.C.J. The consequence of tree pests and diseases for ecosystem services. Science 2013, 342, 1235773. [CrossRef] [PubMed]

3. Bradshaw, C.J.A.; Leroy, B.; Bellard, C.; Roiz, D.; Albert, C.; Fournier, A.; Barbet-Massin, M.; Salles, J.-M.; Simard, F.; Courchamp, F. Massive yet grossly underestimated global costs of invasive insects. Nat. Commun. 2016, 7, 12986. [CrossRef] [PubMed]

4. Aukema, J.E.; McCullough, D.G.; Holle, B.V.; Liebhold, A.M.; Britton, K.; Frankel, S.J. Historical accumulation of nonindigenous forest pests in the continental United States. BioScience 2010, 60, 886-897. [CrossRef]

5. García Morales, M.; Denno, B.D.; Miller, D.R.; Miller, G.L.; Ben-Dov, Y.; Hardy, N.B. ScaleNet: A Literature-Based Model of Scale Insect Biology and Systematics. Database. Available online: http://scalenet.info/catalogue/ (accessed on 10 April 2019).

6. Miller, D.R.; Miller, G.L.; Hodges, G.S.; Davidson, J.A. Introduced scale insects (Hemiptera: Coccoidea) of the United States and their impact on U.S. agriculture. Proc. Entomol. Soc. Wash. 2004, 107, 123-158.

7. Kondo, T.; Esato, T.; Kawai, S. Phenacoccus madeirensis Green (Hemiptera: Pseudococcidae), a recently introduced exotic pest in Japan. Boll. Zool. Agrar. Bachic. Ser. II 2001, 33, 337-341.

8. Shylesha, A.N.; Joshi, S. Occurrence of Madeira Mealybug, Phenacoccus madeirensis Green (Hemiptera: Pseudococcidae) on cotton in India and record of associated parasitoids. J. Biol. Control 2012, 26, 272-273.

9. Graziosi, I.; Minato, N.; Alvarez, E.; Ngo, D.T.; Hoat, T.X.; Aye, T.M.; Pardo, J.M.; Wongtiem, P.; Wyckhuys, K.A. Emerging pests and diseases of South-east Asian cassava: A comprehensive evaluation of geographic priorities, management options and research needs. Pest Manag. Sci. 2016, 72, 1071-1089. [CrossRef]

10. Williams, D.J. Phenacoccus gossypii Townsend \& Cockerell, P. madeirensis Green and some related species (Hemiptera: Pseudococcidae). Bull. Entomol. Res. 1987, 77, 335-356. 
11. Wang, Y.S.; Dai, T.M.; Tian, H.; Wan, F.H.; Zhang, G.F. Phenacoccus madeirensis green (Hemiptera: Pseudococcidae): New geographic records and rapid identification using a species-specific PCR assay. Crop Prot. 2019, 116, 68-76. [CrossRef]

12. Katbeh-Bader, A.; Al-Jboory, I.J.; Kaydan, M.B. First record of the Madeira mealybug, Phenacoccus madeirensis Green (Hemiptera: Pseudococcidae), in Jordan. EPPO Bull. 2019. [CrossRef]

13. Chong, J.H.; Oetting, R.D. Influence of temperature and mating status on the development and fecundity of the mealybug parasitoid, Anagyrus sp. nov. nr. sinope Noyes and Menezes (Hymenoptera: Encyrtidae). Environ. Entomol. 2006, 35, 1188-1197. [CrossRef]

14. Oetting, R.; Hudson, W.; Braman, K. Ornamental, lawn and turf insects. In Summary of Losses from Insect Damage and Costs of Control in Georgia 2001; Guilebeau, P., Roberts, P., Hinkle, N., Eds.; University of Georgia: Athens, GA, USA, 2002; pp. 21-23.

15. Fürsch, H. New African species of Scymnini (Coleoptera, Coccinellidae) as predators of cassava pests. Rev. Zool. Afric. 1987, 100, 387-394.

16. Pijls, J.W.A.M.; van Alphen, J.J.M. On the coexistence of the cassava mealybug parasitoids Apoanagyrus diversicornis and A. lopezi (Hymenoptera: Encyrtidae) in their native South America. Bull. Entomol. Res. 1996, 86, 51-59. [CrossRef]

17. Green, E.E. Observations on the Coccidae of the Madeira Islands. Bull. Entomol. Res. 1923, 14, 87-89. [CrossRef]

18. Franco, J.C.; Russo, A.; Marotta, S. An annotated checklist of scale insects (Hemiptera: Coccoidea) of Portugal, including Madeira and Azores Archipelagos. Zootaxa 2011, 3004, 1-32. [CrossRef]

19. Longo, S.; Mazzeo, G.; Russo, A. Biological observations on some scale insects (Homoptera: Coccoidea) in Sicily. Isr. J. Entomol. 1995, 29, 219-222.

20. Matile-Ferrero, D.; Germain, J.F. Eriococcus munroi (Boratynski), nouveau ravageur du Lavandin en France, et note sur deux Pseudococcines nouvelles pour la France (Hemiptera, Eriococcidae et Pseudococcidae). Bull. Soc. Entomol. Fr. 2004, 109, 191-192.

21. Beltrà, A.; Soto, A. New records of mealybugs (Hemiptera: Pseudococcidae) from Spain. Phytoparasitica 2011, 39, 385-387. [CrossRef]

22. Kaydan, M.B.; Erkiliç, L.; Ülgentürk, S. An invasive mealybug species Phenacoccus madeirensis Green (Hemiptera: Coccoidea, Pseudococcidae) introduced recently into Turkey. Turk. Bull. Entomol. 2012, 2, 67-74.

23. Halima-Kamel, M.B.; Germain, J.F.; Mdellel, L.; Abdelaoui, K. Phenacoccus madeirensis (Hemiptera: Pseudococcidae): A new species of mealybug in Tunisia. EPPO Bull. 2014, 44, 176-178. [CrossRef]

24. Albert, R.; Köppler, K.; Schrameyer, K. New pests on the rise. Gemüse 2013, 49, 10-15.

25. Jansen, M.G.M.; Ben-dov, Y.; Kaydan, M.B. New records of scale insects from Crete island, Greece (Hemiptera: Coccoidea). Bull. Soc. Entomol. Fr. 2010, 115, 483-484.

26. Kinjo, M.; Nakasone, F.; Hicia, Y.; Nagamine, M. Scale insects on mango in Okinawa prefecture. Proc. Assoc. Plant Prot. Kyushu 1996, 42, 125-127. [CrossRef]

27. Tok, B.; Kaydan, M.; Mustu, M.; Ulusoy, M. Development and life table parameters of Phenacoccus madeirensis Green (Hemiptera: Pseudococcidae) on four ornamental plants. Neotrop. Entomol. 2016, 45, 389-396. [CrossRef] [PubMed]

28. Wu, S.A.; Nan, N.; Lu, Y. Phenacoccus madeirensis (Hemiptera: Coccoidea: Pseudococcidae), a newly invasive mealybug in mainland China. Entomotaxonomia 2010, 32, 8-12.

29. Muniappan, R.; Shepard, B.M.; Watson, G.W.; Carner, G.R.; Rauf, A.; Sartiami, D.; Hidayat, P.; Afun, J.V.K.; Goergen, G.; Ziaur Rahman, A.K.M. New records of invasive insects (Hemiptera: Sternorrhyncha) in Southeast Asia and West Africa. J. Agric. Urban Entomol. 2011, 26, 167-174. [CrossRef]

30. Williams, D.J. Mealybugs of Southern Asia; The Natural History Museum: London, UK; Southdene: Kuala Lumpur, Malaysia, 2004; pp. 668-669.

31. Abbas, G.; Arif, M.; Saeed, S.; Karar, H. A new invasive species of genus Phenacoccus Cockerell attacking in Pakistan. Int. J. Agric. Biol. 2009, 11, 54-58.

32. Wei, J.F.; Zhang, H.F.; Zhao, W.Q.; Zhao, Q. Niche shifts and the potential distribution of Phenacoccus solenopsis (Hemiptera: Pseudococcidae) under climate change. PLoS ONE 2017, 12, e0180913. [CrossRef]

33. Jarnevich, C.S.; Stohlgren, T.J.; Barnett, D.; Kartesz, J. Filling in the gap: Modelling native species richness and invasions using spatially incomplete data. Divers. Distrib. 2006, 12, 511-520. [CrossRef] 
34. Chong, J.H.; Oetting, R.D.; van Iersel, M.W. Temperature effects on the development, survival, and reproduction of the Madeira mealybug, Phenacoccus madeirensis Green (Hemiptera: Pseudococcidae), on Chrysanthemum. Ann. Entomol. Soc. Am. 2003, 96, 539-543. [CrossRef]

35. Kadmon, R.; Farber, O.; Danin, A. Effect of roadside bias on the accuracy of accuracy of predictive maps produced by bioclimatic models. Ecol. Appl. 2004, 14, 401-413. [CrossRef]

36. Wei, J.F.; Niu, M.M.; Feng, J.N. Diversity and distribution patterns of scale insects in China. Ann. Entomol. Soc. Am. 2015, 109, 405-414. [CrossRef]

37. Kramer-Schadt, S.; Niedballa, J.; Pilgrim, J.D.; Schröder, B.; Lindenborn, J.; Reinfelder, V.; Stillfried, M.; Heckmann, I.; Scharf, A.K.; Augeri, D.M.; et al. The importance of correcting for sampling bias in MaxEnt species distribution models. Divers. Distrib. 2013, 19, 1366-1379. [CrossRef]

38. Phillips, S.J.; Dudik, M.; Elith, J.; Graham, C.H.; Lehmann, A.; Leathwick, J.; Ferrier, S. Sample selection bias and presence-only distribution models: Implications for background and pseudo-absence data. Ecol. Appl. 2009, 19, 181-197. [CrossRef] [PubMed]

39. Li, G.Q.; Du, S.; Guo, K. Evaluation of limiting climatic factors and simulation of a climatically suitable habitat for Chinese sea buckthorn. PLoS ONE 2015, 10, e0131659.

40. Rodriguez-Castaneda, G.; Hof, R.A.; Jansson, R.; Harding, L.E. Predicting the fate of biodiversity using species' distribution models: Enhancing model comparability and repeatability. PLoS ONE 2012, 7, e44402. [CrossRef]

41. Wei, J.F.; Zhao, Q.; Zhao, W.Q.; Zhang, H.F. Predicting the potential distribution of the invasive cycad scale Aulacaspis yasumatsui (Hemiptera: Diaspididae) under different climate change scenarios and the implications for management. PeerJ 2018, 6, e64832. [CrossRef]

42. Medley, K.A. Niche shifts during the global invasion of the Asian tiger mosquito, Aedes albopictus Skuse (Culicidae), revealed by reciprocal distribution models. Glob. Ecol. Biogeogr. 2010, 19, 122-133. [CrossRef]

43. Bell, D.M.; Bradford, J.B.; Lauenroth, W.K. Early indicators of change: Divergent climate envelopes between tree life stages imply range shifts in the western United States. Glob. Ecol. Biogeogr. 2014, 23, 168-180. [CrossRef]

44. Hijmans, R.J.; Cameron, S.E.; Parra, J.L.; Jones, P.G.; Jarvis, A. Very high resolution interpolated climate surfaces for global land areas. Int. J. Climatol. 2005, 25, 195-204. [CrossRef]

45. Heikkinen, R.K.; Luoto, M.; Araújo, M.B.; Virkkala, R.; Thuiler, W.; Matrin, T. Methods and uncertainties in bioclimatic envelope modelling under climate change. Prog. Phys. Geogr. 2006, 30, 751-777. [CrossRef]

46. Warren, D.L.; Glor, R.E.; Turelli, M. ENMTools: a toolbox for comparative studies of environmental niche models. Ecography 2010, 33, 607-611. [CrossRef]

47. Sultana, S.; Baumgartner, J.B.; Dominiak, B.C.; Royer, J.E.; Beaumont, L.J. Potential impacts of climate change on habitat suitability for the Queensland fruit fly. Sci. Rep. 2017, 7, 13025. [CrossRef] [PubMed]

48. Moss, R.H.; Edmond, J.A.; Hibbard, K.A.; Manning, M.R.; Rose, S.K.; van Vuuren, D.P.; Carter, T.R.; Emori, S.; Kainuma, M.; Kram, T.; et al. The next generation of scenarios for climate change research and assessment. Nature 2010, 463, 747-756. [CrossRef]

49. Aljaryian, R.; Kumar, L.; Taylor, S. Modelling the current and potential future distributions of the sunn pest Eurygaster integriceps (Hemiptera: Scutelleridae) using CLIMEX. Pest Manag. Sci. 2016, 72, 1989-2000. [CrossRef] [PubMed]

50. Beaumont, L.J.; Hughes, L.; Poulsen, M. Predicting species distributions: Use of climatic parameters in BIOCLIM and its impact on predictions of species' current and future distributions. Ecol. Model. 2005, 186, 251-270. [CrossRef]

51. Wang, X.Y.; Huang, X.L.; Jiang, L.Y.; Qiao, G.X. Predicting potential distribution of chestnut phylloxerid (Hemiptera: Phylloxeridae) based on GARP and Maxent ecological niche models. J. Appl. Entomol. 2009, 134, 45-54. [CrossRef]

52. Marchioro, C.A.; Krechemer, F.S. Potential global distribution of Diabrotica species and the risks for agricultural production. Pest Manag. Sci. 2018, 74, 2100-2109. [CrossRef]

53. Merow, C.; Smith, M.J.; Silader, J.A. A Practical guide to MaxEnt for modeling species' distributions: What it does, and why inputs and settings matter. Ecography 2013, 36, 1058-1069. [CrossRef]

54. Tang, J.H.; Li, J.H.; Lu, H.; Lu, F.P. Potential distribution of an invasive pest, Euplatypus parallelus, in Chinaas predicted by Maxent. Pest Manag. Sci. 2018, 75, 1630-1637. [CrossRef] [PubMed] 
55. Barredo, J.I.; Strona, G.; de Rigo, D.; Caudullo, G.; Stancanelli, G.; San-Miguel-Ayanz, J. Assessing the potential distribution of insect pests: Case studies on large pine weevil (Hylobius abietis $\mathrm{L}$ ) and horse-chestnut leaf miner (Cameraria ohridella) under present and future climate conditions in European forests. EPPO Bull. 2015, 45, 273-281. [CrossRef]

56. Ørsted, I.V.; Ørsted, M. Species distribution models of the Spotted Wing Drosophila (Drosophila suzukii, Diptera: Drosophilidae) in its native and invasive range reveal an ecological niche shift. J. Appl. Ecol. 2018, 56, 423-435. [CrossRef]

57. Phillips, S.J.; Anderson, R.P.; Dudik, M.; Schapire, R.E.; Blair, M.E. Opening the black box: An open-source release of MaxEnt. Ecography 2017, 40, 887-893. [CrossRef]

58. Muscarella, R.; Galante, P.J.; Soley-Guardia, M.; Boria, R.A.; Kass, J.M.; Uriarte, M.; Anderson, R.P. ENMeval: An R package for conducting spatially independent evaluations and estimating optimal model complexity for MaxEnt ecological niche models. Methods Ecol. Evol. 2014, 5, 1198-1205. [CrossRef]

59. Wang, F.; Wang, D.; Guo, G.; Hu, Y.H.; Wei, J.F.; Liu, J.Z. Species delimitation of the Dermacentor ticks based on phylogenetic clustering and niche modeling. PeerJ 2019, 7, e69911. [CrossRef] [PubMed]

60. Lobo, J.M.; Jiménez-Valverde, A.; Real, R. AUC: A misleading measure of the performance of predictive distribution models. Glob. Ecol. Biogeogr. 2008, 17, 145-151. [CrossRef]

61. Osorio-Olvera, L.; Vijay, B.; Narayani, B.; Jorge, S.; Falconi, M. Ntbox: From Getting Biodiversity Data to Evaluating Species Distribution Models in a Friendly GUI Environment. R Package Version 0.2.5.4. 2018. Available online: https://github.com/luismurao/ntbox (accessed on 15 June 2019).

62. Sarma, R.R.; Munsi, M.; Ananthram, A.N. Effect of climate change on invasion risk of Giant African Snail (Achatina fulica Ferussac, 1821: Achatinidae) in India. PLoS ONE 2015, 10, e0143724.

63. Richardson, D.M.; Iponga, D.M.; Roura-Pascual, N.; Krug, R.M.; Milton, S.J.; Hughes, G.O.; Thuiller, W. Accommodating scenarios of climate change and management in modelling the distribution of the invasive tree Schinus molle in South Africa. Ecography 2010, 33, 1049-1061. [CrossRef]

64. Padalia, H.; Srivastava, V.; Kushwaha, S.P.S. How climate change might influence the potential distribution of weed, bushmint (Hyptis suaveolens)? Environ. Monit. Assess. 2015, 187, 210. [CrossRef]

65. Romero-Alvarez, D.; Escobar, L.E.; Varela, S.; Larkin, D.J.; Phelps, N.B.D. Forecasting distributions of an aquatic invasive species (Nitellopsis obtusa) under future climate scenarios. PLoS ONE 2017, 12, e0180930. [CrossRef] [PubMed]

66. Bellard, C.; Thuiller, W.; Leroy, B.; Genovesi, P.; Bakkenes, M.; Courchamp, F. Will climate change promote future invasions? Glob. Chang. Biol. 2013, 19, 3740-3748. [CrossRef] [PubMed]

67. Zhu, G.P.; Peterson, A.T. Do consensus models outperform individual models? Transferability evaluations of diverse modeling approaches for an invasive moth. Biol. Invasions 2017, 19, 2519-2532. [CrossRef]

68. Gould, S.F.; Beeton, N.J.; Harris, R.M.B.; Hutchinson, M.F.; Lechner, A.M.; Porfirio, L.L.; Mackey, B.G. A tool for simulating and communicating uncertainty when modelling species distributions under future climates. Ecol. Evol. 2014, 4, 4798-4811. [CrossRef] [PubMed]

69. Watson, G.W.; Williams, D.J.; von Ellenrieder, N.; Kinnee, S.A. Evidence for a cryptic species-group around Phenacoccus madeirensis Green, 1923 (Hemiptera: Pseudococcidae). Pan Pac. Entomol. 2017, 93, 115-126. [CrossRef]

70. Sattayawong, C.; Uraichuen, S.; Suasa-ard, W. Larval preference and performance of the green lacewing, Plesiochrysa ramburi (Schneider) (Neuroptera: Chrysopidae) on three species of cassava mealybugs (Hemiptera: Pseudococcidae). Agric. Nat. Resour. 2016, 50, 460-464. [CrossRef]

71. Nori, J.; Urbina-cardona, J.N.; Loyola, R.D.; Lescano, J.N.; Leynaud, G.C. Climate change and American Bullfrog invasion: What could we expect in South America? PLoS ONE 2011, 6, e25718. [CrossRef]

72. Warren, D.L. In defense of "niche modeling". Trends Ecol. Evol. 2012, 27, 497-500. [CrossRef]

(C) 2019 by the authors. Licensee MDPI, Basel, Switzerland. This article is an open access article distributed under the terms and conditions of the Creative Commons Attribution (CC BY) license (http://creativecommons.org/licenses/by/4.0/). 